Marquette University

e-Publications@Marquette

College of Education Faculty Research and

Publications

Education, College of

12-1-2009

\title{
Race, Power, and (In)equity Within Two-way Immersion Settings
}

Martin Scanlan

Marquette University, martin.scanlan@marquette.edu

Deborah Palmer

University of Texas at Austin

Accepted version. Urban Review, Vol. 41, No. 5 (December 2009): 391-415. DOI. (C) 2009 Springer. Used with permission.

Shareable Link. Provided by the Springer Nature SharedIt content-sharing initiative. 


\title{
Race, Power, and (In)equity Within Two-way Immersion Settings
}

\section{Authors: Martin Scanlan \& Deborah Palmer}

\begin{abstract}
Two-way immersion schools provide a promising model for service delivery to students who are English language learners. With the goals of bilingualism, academic excellence, and cross cultural appreciation, these schools are designed to build bridges across linguistically heterogeneous student bodies. Yet while empirical evidence demonstrates that the two-way immersion model can be effective in these regards, we know little about how such schools address other dimensions of diversity, including race, ethnicity, class, and disability. This study contributes to filling this gap by critically analyzing these dimensions in the areas of recruitment and retention in two two-way immersion schools.
\end{abstract}

As elementary schools grow increasingly heterogeneous, educational approaches that foster inclusivity across multiple dimensions of diversity become essential to social justice schooling (Frattura and Capper 2007; Sapon-Shevin 2003, 2007; Theoharis 2007). One such approach is the two-way immersion model, which promotes bilingualism, cross cultural competency, and academic excellence (Howard et al. 2003; Senesac 2002). While we know that two-way immersion schools cultivate strong communities across linguistically heterogeneous student bodies (Howard et al. 2003), few empirical studies have examined how these schools address other dimensions of diversity (for an exception, see Palmer 2004).

This article contributes to filling this gap by critically analyzing admission practices in two two-way immersion schools. Specifically, we examine how nonlinguistic dimensions of diversity, including race, ethnicity, class, and disability, affect recruitment and retention in two such schools. We interrogate the impact that English-dominant, mainstream districts or systems can have on the enactment of social justice education in a two-way school or program. Our cross-case comparison allows us to complicate notions of diversity and equity in two-way schools, an important step in helping these schools succeed in the social justice missions they espouse.

\section{A Critical Approach to Two-way Immersion}

Two-way immersion education (alternately referenced as dual immersion) promotes bilingualism, cross-cultural appreciation, and academic success (Howard et al. 2003). In contrast with most models of service delivery for English language learners, schools practicing two-way immersion do not segregate students into linguistically homogenous groupings (Ovando 2003). 1 Scanlan \& Palmer 
Instead, the two-way immersion model purposefully integrates students who are dominant in English with students who are dominant in a minority language and students who are bilingual. For the schools in this article, as is typical of two-way immersion schools in the United States, this minority language is Spanish. Thus, one of the strengths of the two-way immersion model is its purposeful inclusion of such diverse communities as immigrant Latinos, native US-born Latinos, and Anglo children in the same classroom. In two-way classrooms, curriculum is delivered in both English and the minority language, with the goal of bilingualism and biliteracy for all students, including English native speakers. This additive approach to bilingualism stresses the value for all children in building language and literacy skills in two languages (Garcia and Jensen 2007; Zentella 1997). By way of contrast, Zentella describes the subtractive approach that is typical of most school communities:

The diverse linguistic abilities that Latinos learn in their communities are not tapped by the educational system, which adopts a subtractive instead of an additive approach; that is, the standard English dialect is viewed as a substitute for all the varieties of Spanish and other nonstandard dialects of English that children bring to school, not as an important addition to their verbal repertoire. (p. 123)

Evidence abounds supporting the academic and linguistic outcomes of well designed two-way immersion educational communities (Calderon and Minaya-Rowe 2003; Howard et al. 2003; Perez 2004), and they are growing in number nationally (Center for Applied Linguistics 2005). Evidence also points to these programs' ability to reach across traditional barriers to bring diverse communities together in public schools. While Latino families often experience schools as unwelcoming (Flores and Murillo 2001; Ramirez et al. 1991; Rolon 2003; Rolon-Dow 2005), two-way immersion schools foster strong levels of parent/caregiver engagement (Rubio 1995).

While recognizing these strengths to two-way immersion as a service delivery model, especially for students who are English language learners, we approach this analysis with the skepticism that a critical epistemology provides. Critical epistemologies promote the investigation, interpretation, and critique of suffering and oppression within society (Capper 1998; Guba and Lincoln 2001; Kincheloe and McLaren 2000; McLaren and Giarelli 1995). Our critical epistemology draws on both critical race theory (CRT) and Latino/a critical race (Lat/Crit) theory. According to Ladson-Billings (1999), the lens of CRT can help researchers "expose racism in education and propose radical solutions for addressing it" (p. 27). Originally emerging from the legal tradition, CRT makes the argument that economic forces drive the continued pervasiveness of racism and marginalization of communities of color. Racism refers to the manifestation of 2 Scanlan \& Palmer 
institutional power that benefits Whites and marginalizes people of color in the United States (Solorzano and Yosso 2002). Because someone must always be on the bottom in a capitalist system, middle class and white communities depend on the continued existence of inequities among races and classes in order to maintain their political and economic power. While some forms of overt racism have become unacceptable in our society, nothing short of an economic revolution would erase inequities from our society, whether based on race or class or some other factor. In fact, CRT points out that racism remains alive and well in institutional forms that are barely below the surface. Schools, being institutions that serve those in power, reserve the "absolute right to exclude" certain children through various means, including magnet programs, tracking, access to advance courses, etc. (Ladson-Billings 2005, p. 146). In this way CRT recognizes the ubiquitous manifestations of racism at personal, institutional, and societal levels and emphasizes the importance of drawing upon the experiential knowledge of people of color in understanding and combating racism (Lynn and Adams 2002).

Lat/Crit grew out of CRT to more explicitly address to issues of marginalization affecting Latina/o communities (Valdes 1996) and the complexities that language, culture, gender, ethnicity, immigration, and colonization play on racialized experiences of Latinos (Delgado Bernal 2002; Rolon-Dow 2005). As Villenas et al. (1999), CRT and Lat/Crit can provide a lens for "interpreting the schooling experiences of ... [Latino] students in ways that situate family education, culture, and language as strengths while pointing the finger at schools and the ways in which schools function to disenfranchise these students and their families" (p. 35). Rolon-Dow (2005) illustrates how pairing the CRT and Lat/Crit frameworks creates a powerful tool to critique the institutionalization of race/ethnicity-based forms of subordination and articulate a transformative praxis for countering such injustice.

Drawing from both CRT and Lat/Crit, our critical epistemology framework emphasizes inclusivity across multiple dimensions of diversity, critiquing structures that exclude students as inherently unjust. This extends beyond class, race, ethnicity, sexual orientation and gender to include dimensions of exceptionality (Frattura and Capper 2007; Sapon-Shevin 2007; Theoharis 2007). Sapon-Shevin (2007) describes inclusive education as values and practices "that support the belief that all students in a school, regardless of their strengths, weaknesses, or labels - should be full members of the general education school community, with their individual needs met within that general education context" (p. xii). Simply put, our critical epistemology strives to be holistic.

Viewed from this critical epistemological vantage, we find the dual immersion model

\section{Scanlan \& Palmer}


paradoxical. On one hand, it promotes important social justice goals: bilingualism, cross-cultural appreciation, and academic success for Latino students who are typically underserved in schools. The design of the model heterogeneously mixes students across one dimension of diversity: language. On the other hand, in practice, nonlinguistic dimensions of diversity are often unexplored in dual immersion schools (Palmer 2005; Petrovic 2005; Valdés 1997). In this article we endeavor to enrich our understanding of these paradoxes by delving into admissions practices in two-way immersion schools. Specifically, we examine how nonlinguistic dimensions of diversity affect recruitment and retention in two such schools. One, Medgar Evers School (all names are pseudonyms), develops a strand two-way program to address language and academic needs of bilingual Latino students while explicitly ignoring the racial segregation between two-way classrooms and so-called "mainstream" classrooms at the school. The other, Juan Diego School, makes issues of ethnicity explicit in purposefully serving Latino students. The analysis shows that beyond ethnicity, some dimensions of diversity, such as class, are addressed proactively (if not completely), while others, such as disability, are avoided.

\section{Methods}

Medgar Evers and Juan Diego Schools are both elementary schools located in metropolitan areas in the Western United States. Both schools were originally the subjects of independent studies, and we are presenting here analysis from a cross-case comparison. At Medgar Evers, the focus of the original study was a highly effective teacher in the two-way immersion second grade classroom, although observation and interview data were collected throughout the school. Research questions involved close examination of the discourses around language and power, equity and diversity in the classroom and its context. The researcher (Palmer) had previously served part-time on the staff at the school, affording an insider/outsider perspective. Juan Diego was selected as one of only a handful of two-way immersion Catholic schools that could be located nationally. The original study examined how this school promoted inclusivity across non-linguistic dimensions of diversity, including race, ethnicity, socioeconomic status, and exceptionality. The researcher (Scanlan) drew on experience as a Catholic school educator and researcher to gain access to the school community. In both studies, we gathered data through interviews, observations, and archival data. Semi-structured interviews were conducted with administrators, teachers, parents and caregivers in both schools. Interviews averaged an hour in length and were conducted privately at the school site or in interviewees' homes. All interviews were transcribed and coded using constant comparative methodology

\section{Scanlan \& Palmer}


(Maxwell 1998, 2001; Wolcott 1990). Observations were made during multiple site visits to each school, and multiple contacts via phone and email over the course of one school year. Extensive field notes were made during these site visits, which were also coded. In addition, we gathered archival documentation regarding five dimensions of each school: (a) accounts of the school history, (b) demographic enrollment data on gender, race and ethnicity, home language, socioeconomic status, and disability, (c) student attendance and academic achievement data, (d) school mission and vision statements, and (e) school long-term/strategic planning. Further descriptions of data gathering are presented elsewhere for both Medgar Evers (Palmer 2008) and Juan Diego (Scanlan 2008).

For the cross-case comparison presented here, we analyzed these two sets of data using constant comparative methodology (Glesne 1999). During this analysis we initially exchanged independent accounts of the two school communities and began to dialogue about the commonalities and discrepancies between the two cases. To these initial dialogues we each brought our own personal histories to the table. While both of us are currently university faculty, one of us (Scanlan) had spent time as an administrator starting a dual immersion school and serving on its board of directors, as well as extensive experience as a teacher and administrator in Catholic elementary schools serving traditionally marginalized students. The other (Palmer) had been a classroom teacher and a teacher coach in various urban settings, including two years teaching bilingually at Spanish/English two-way immersion public schools. As our dialogues progressed we were critically reflective regarding the biases we brought to this study based on our previous positions. Both of us were predisposed to view the two-way immersion approach to bilingual education as advantageous both academically and in promoting social justice in schooling. One of us (Scanlan) was particularly curious as to the efficacy of this model within a Catholic school setting, as little evidence exists of effective bilingual Catholic schools. The other (Palmer), was particularly interested in the role of language and power and the influence of outside discourses on the dynamics of two-way immersion schools and classrooms.

From these initial dialogues it became clear that nonlinguistic dimensions of diversity were integral to understanding both Medgar Evers and Juan Diego. We narrowed our focus further to consider how elements of race, ethnicity, class, and disability affected recruitment and retention in both schools. This led us each to reanalyze our data considering these specific dimensions. Again, we presented our findings to one another. We then engaged in an iterative process of sifting through these findings to identify the most salient points that extended across the cases. These stages of analyses lasted six months, during which time we regularly communicated by email,

\section{Scanlan \& Palmer}


phone, and on occasion in person. We presented these initial findings (Scanlan and Palmer 2007). Feedback from this presentation helped us more clearly present the critical epistemology framework guiding our analysis.

\section{Results}

We will first present a summary of evidence regarding how admissions practices impact the classroom and school level communities within the school around multiple dimensions of diversity. We begin with Medgar Evers School, and follow with Juan Diego School. We will then contrast these data and discuss the implications for dual immersion schools in particular, and education for students who are English language learners in general.

\section{Medgar Evers School}

In an economically and racially diverse small city in a large metropolitan area of California, Medgar Evers (MES) is a small public elementary school serving approximately 350 students in grades $\mathrm{K}-5$. The school has a strand 90:10 two-way immersion program, so that one classroom out of three at each grade level is part of the two-way immersion program. The remaining classrooms are served by English-only speaking teachers, and are referred to by interview participants as "mainstream" classrooms, although the majority of students in these classrooms are African-American and Latino children. While not strictly a neighborhood school, MES (especially the non-two-way "mainstream" program) predominantly serves children from the surrounding neighborhood, which is historically African American but in recent years has been receiving a steady stream of Latino immigrants. In the district lottery that assigns pupils to the school, which occurs in February, two-way classrooms are filled separately from the mainstream classrooms. The district in which MES operates, like the school, serves a diverse student body. Overall, the district serves a student population that is approximately $15 \%$ Hispanic/Latino, $33 \%$ African American, and 29\% non-Hispanic White (California Department of Education 2007). The following section will offer a historical perspective on the development of the two-way immersion strand at MES, and then an analysis of its current challenges.

\section{Origins of the Two-way Immersion Program}

Before 1997, the school (then called Jefferson) had a transitional bilingual education program to serve its English learners. One of the bilingual teachers, Andrea, new to the school in 1995, was impressed with the high level of parent involvement from the Spanish speaking community. Parents had been activated by a court case involving the education of LEP children in the district that had only recently been settled. They were unhappy with the lack of articulation

\section{Scanlan \& Palmer}


within the bilingual program, the lack of collaboration between teachers, and the high level of tension between Black and Latino students on campus, which Andrea attributed to the almost complete segregation that occurred at the school between bilingual and "mainstream" classrooms. Andrea saw her fellow teachers hiding from one another and from the parents by isolating themselves in their classrooms. She agreed with parents' concerns, and saw their active engagement as an opportunity for change. Eager to find some money to support improvement at Jefferson, Andrea sought guidance from a professor at the local university. With his support, Andrea worked hard to pull the community together to explore various approaches to bilingual education. By her description, the process was one of active research, eventually settling on the two-way model as the one most likely to solve their various concerns:

I pretty much organized the parents into a bilingual task force and we started research as a group and we... of course all the teachers were also on board and they had to participate as well and what we did was we looked at all the research that we could about effective programs for children and then we went out and actually visited programs. You know we had site visits all over the area mostly and then we prepared this grant wanting to address all the concerns that I mentioned before and it became really clear that the two-way immersion model was going to address a lot of those. That it was academically rigorous. That the research had indicated that children were more prepared for secondary schooling having extended their home language beyond fifth grade. And that it was going to integrate students and that there was this mutual exchange of knowledge you know and cultural understanding that goes on in two way immersion. So a lot of the stuff that we were concerned about would be addressed.

In 1996, this task force wrote and won a federal Title VII Grant to transform the transitional program into an innovative and more academically powerful "two-way immersion" program. With the grant, Andrea became the bilingual resource teacher for the school, gradually implementing the two-way program beginning with kindergarten, purchasing materials to benefit the entire school, and eventually moving for 1 year into the role of principal before leaving the school in 2002 , the year before this study.

Interestingly, the grant was won with only tacit approval from the district superintendent, who according to Andrea, "respected the work I had done and he felt that it was worthwhile but I think he always saw it as a sort of experiment. And nothing he could put his full support behind." The year the grant was won, the school had a principal who in Andrea's words was "very anti-bilingual education and she kept saying we needed to downplay bilingual ed because we were going to scare potential parents away from our program if they knew there was a bilingual program on the campus." Thus, while parents and teachers gathered force behind the 7 Scanlan \& Palmer 
development of a new program at Jefferson, administrative support was shaky.

This can possibly be explained with some further perspective on this particular district's views of the tension between integration and bilingual education. Throughout the district there is a high level of concern about maintaining a racially integrated school community. While integration can be defined in many ways, this district clearly defined it as serving children from different racial and ethnic backgrounds in the same schools, in as close as possible to balanced numbers. Serving a traditionally progressive city, this school district was one of the first in the nation to voluntarily desegregate its schools in the late 1960s. Through years of shifting national climate on the issue of desegregation, this district has worked hard to maintain integrated, diverse schools. Because of Proposition 209, a law passed by voter initiative in the state of California in 1996, race is not allowed as a factor in the assignment of students to schools. However, the district has developed a system using zip codes that attempts (with mixed results) to maintain racial and ethnic diversity in the schools. In school board meetings and district level planning meetings, "integrated" is for all intents and purposes equated with "equitable."

More importantly, the district uses this system to avoid school enrollments that are homogenous across race and ethnicity. A significant body of research supports the relationship between integration and equity in schools (Orfield 1981; Orfield and Lee 2005; Schofield 1995). Orfield and Lee's (2005) work suggests that integrated school environments would make a difference for poor and minority students and help reduce racist attitudes in society. However, research also indicates that merely having diverse children share a campus does very little to promote equity, particularly in terms of reducing the achievement gap between white students and students of color, without explicit efforts at educating for diversity (Fuller and Elmore 1996; Noguera 2003; Olsen 1987).

In the discourse of meetings in this district, the subtleties of "real" integration and educating for diversity are often overlooked, while any form of intentional segregation for any reason is subject to spurning. Because many approaches to bilingual education, including the transitional approach that the district had been using, requires the separation of English learners (i.e. mostly Latino children) for several years, it has been a topic of ongoing challenge in this district. Andrea and others recognized internal segregation to be an issue in effective implementation of the transitional bilingual program at Jefferson, and the community's choice of a two-way program was meant to integrate the classrooms. However, with lukewarm district-level administrative support and local biases among teachers who have been with the school (and district) for many years, the resulting change did not fully address the challenges Andrea noted.

\section{Scanlan \& Palmer}




\section{Current Challenge of Internal Segregation}

Medgar Evers today maintains rich diversity in its overall school population, possibly even more so than in 1997, due to the likely increase in enrollment of white families coming to the school expressly for the dual immersion program. Yet just as with the old transitional bilingual program, there remains a sharp contrast between the diversity of the dual immersion classes and that of so-called 'mainstream' classes. As one 'mainstream' teacher with over 15 years' experience at the school explained, "On paper our school looks integrated and it's less integrated than you might think if you walk into different classrooms." Although the entire school population is approximately $30 \%$ African American, on average dual immersion classes contain only about $5 \%$ African American students, leaving the 'mainstream' classrooms filled almost $50 \%$ with African American students. Latinos and whites in the larger school are represented by 38 and $25 \%$, respectively. In the two-way program they are maintained artificially with $50 \%$ Latino Spanish speakers and approximately $45 \%$ whites. It is rare to find a child of any other ethnic or linguistic background than these three groups in the dual immersion program at MES, while the larger school actually contains numerous other groups including Ethiopian, Sri Lankan, Japanese, and NES European (Charts 1, 2, and 3, Table 1).

Remembering that according to Andrea one of the original goals of the program was to integrate the African American and Latino communities, one might be led to ask, why are there not more African American students in the two-way immersion classrooms? Indeed, Andrea herself lamented that one area in which MES still needed to improve was that of recruiting African American families into the two-way immersion program. She saw this as the best solution to the school's internal segregation, and as an excellent opportunity for the school, and for the black students, to shine.

In part, recruitment of African American students has been difficult because of district-level gatekeeping policies that seem intractable. First of all, as she explained, because of Proposition 209, a state law prohibiting the use of race as a factor in admissions to public institutions, the district refuses to use race as a factor in forming the dual immersion cohort each year. Andrea explains, "supposedly they can't. They can't use race. But l've seen plenty of examples of people using race and getting away with it. But our district seems to think that they have to ... in this situation they're going to follow the rules."

This leaves recruitment up to the extra efforts of school personnel to reach out to inform African American families at local preschools in the months before the February lottery for kindergarten placement that will otherwise inevitably fill the ten English-speaking dual immersion

\section{Scanlan \& Palmer}


slots with middle class white families. Staff members express doubts as to whether this tactic will ever truly become effective. For a wide variety of reasons involving institutional and cultural barriers that go far beyond the reaches of this school, many African American students enter the school lottery much later than February, long after slots are filled for competitive programs like the MES two-way immersion. According to Andrea, their preschool recruitment is likely already having the effect it should: on average, one slot of every ten goes to a black family:

Our white families are well aware. It's publicized in their circles. And it's on the radar screen. And they're aggressively seeking it out. So if I had to guess l'd probably say it's ... ninety percent white families applying and ten percent African American. So it doesn't surprise me that there's one (African American) child chosen each year, one or two.

In addition to these explicit gatekeeping policies, there is more subtle gatekeeping operating in the form of key personnel's attitudes towards the appropriateness of two-way immersion education for African American students. There is a widespread (and mostly unspoken) assumption among staff that the two-way immersion program would not attract-and perhaps would not even be appropriate for-the African American students from the surrounding neighborhood. When asked whether she thought that making Medgar Evers a school wide two-way immersion program might increase the number of African American students enrolling in dual immersion, a mainstream teacher confided, "I doubt it. And I'm not actually ... sure it is a good idea if your Standard English is not so great in the first place to go into a program where you're trying to learn basically a third language and you don't have early experiences that build language ...." This assumption, that African American families do not provide children with language-building experiences, reflects a powerful deficit orientation towards her black students. The English Language Development (ELD) Lead Teacher, whose job involves supporting non-two-way teachers in their efforts to effectively serve the English learners in their classrooms (in English only), echoed the mainstream teacher's doubts about the prospects of recruiting African Americans into the two-way immersion program, as well as her reservations about whether dual immersion would benefit African American students. In her words, "I don't know if two-way immersion is good for the African American kids. I don't know how you help [African American] kids learn Standard English." Currently, she observed that it "concerns" her that the Latino children who are in the "mainstream" program, "the EL kids, are coming out and they're speaking Black English. They're not speaking Standard English and they don't know that they're speaking Black English." She also expressed concern that the Latino children were "copying the behaviors of those African American kids (who are) more of a behavior problem." It seems as 10 Scanlan \& Palmer 
though this teacher fears the possibility that the Latino and African American students might unite in opposition to the white teachers (like her) who are attempting to exert control on them. Her stereotypes of African American children lead her to conclude that exposing Latino children to African American children is not the answer; rather, the answer lies in exposing both groups of minority children to more "peers that are high level," a thinly disguised gloss for white, middle class children, who she feels have left the "mainstream" program since the advent of dual immersion.

Such doubts about the wisdom of recruiting African American students into the two-way program, emerging from a racist, deficit-ridden view of African American children and families, would appear to undermine any efforts at recruitment. Playing as they do upon the mainstream stereotype of African American students as incompetent users and learners of language, as exhibitors of problematic behaviors, and as in need of remedial, as opposed to enrichment, experiences, these attitudes amongst the staff also undermine Black students' academic efforts at the school in general. From a Critical Race Theory (CRT) perspective, teachers' racism operating to exclude black students from opportunities and to undermine their success in school contexts is not surprising. Rather, the systemic exclusion of Blacks from power, through denying them access to what could potentially be a powerful and enriching education, is to be expected. The two-way second grade teacher, Melanie (a white woman), shared her conviction that her colleagues' resistance to Black children and families was due to their unexamined racisms. According to Melanie, her English-only colleagues “don't want the Black kids in their class, point blank. Those are their problem kids. They want more of the upper middle class white kids and less of the lower income Black kids who they have discipline problems with. So it creates a conflict in our staff." In general, two-way staff support the expansion of the two-way program at MES.

While teachers are not necessarily forthcoming about their own deficit orientations and racist attitudes toward African American students, they will readily acknowledge that internal segregation creates serious problems for non-two-way immersion students at MES. There is broad agreement on this point. One 'mainstream' teacher pointed out that, while dual immersion students are in a special enrichment language program, the 'mainstream' students are "without the benefit of being in a 'chosen' program. It's just who's there." Appealing to the district's long-standing commitment to desegregation in the interests of racial equity, she argued that this two-tiered system is detrimental to the academic progress of 'mainstream' children. In addition, the two-way immersion classes have more than their fair share of supportive middle class parents. While some would argue that many of those parents are only in the school due to the presence of

\section{Scanlan \& Palmer}


the two-way program (the data on this point are ambiguous), 'mainstream' teachers perceive an inherent unfairness in the visible discrepancy. They brand the two-way program as "elitist," a label that is only reinforced by these families' assertiveness towards the leadership of the school and district. The two-way coordinator, in a grant-funded position designed to help support the two-way teachers and parents as the program is getting established, related a recent incident that demonstrated white middle-class parent audacity. Parents came to a district meeting to demand that upper grade two-way immersion teachers be given aides since recent budget cuts required their children (like other children in the district) to be placed in split-grade classes in the upper grades:

The two-way immersion parent association would show up at the task force (district meeting). They were advocating for their kids. And I have to say I look at them like, your kids can't have that if everybody else doesn't have that. You know they want a classroom aide ... And okay if we give the immersion program a classroom aide we're going to have to give everybody else a classroom aide and there's not money for that.

The sense of entitlement of white middle-class two-way immersion parents guarantees the success of their own children, and carries along the Latino children who share their classrooms; however, because of the separate nature of the two strands at the school, there are times when this is at the expense of the children in the 'mainstream' classes. Resources, particularly money from federal grants designed to put the two-way program in place, was plentiful enough at the school during the first years of implementation, according to Andrea, and she and others specifically wrote the grants in order to "benefit everybody and really try to treat the whole school as one community." However, as resources have dwindled, tensions between two-way and "mainstream" programs have increased. According to a CRT frame, the push for entitlement of the white families in the face of scarcity of resources effectively serves to keep the powerful in power. This points to a central paradox raised in the case of MES: two-way immersion education often explicitly works to exploit the sense of entitlement of powerful members of the school community in order to benefit all members of a school, and it works for those members of the underclass who have managed to gain entrance into the two-way community; what is the impact on those who do not happen to be counted as members of that exclusive community?

\section{Complicating Definitions of a Diverse School Experience}

The two-way program at MES appears very similar to a magnet "school-within-a-school", a common attempt to attract racial and socioeconomic diversity in poor, minority schools by developing an exciting magnet program that, for all intents and purposes, has little to no 12 Scanlan \& Palmer 
connection with the larger school. Magnet schools-within-schools, more often found in high schools than in elementary schools, remain controversial. Some research has demonstrated that the mere presence of a magnet school on campus improves educational quality (Blank 1990; Blank et al. 1996; Rossell 1990). On the other hand, critics argue that much like tracking or ability-grouping, internally segregated magnet programs have been shown to have little of the positive effect of true integration upon the academic achievement of minority students (Fuller and Elmore 1996; Oakes 2005). We will explore these dimensions in our discussion, below, but first turn to consider the case of another two-way immersion setting, Juan Diego School.

\section{Juan Diego School}

The admissions processes in Juan Diego School (JDS), as in MES, address multiple dimensions of diversity in complicated and contradictory manners. The evidence shows that the education of Latinos is the most salient dimension of diversity addressed in the school community, directly impacting recruitment and retention, and central to the mission. (Research participants at JDS use the terms Latino and Hispanic interchangeably and refer to Whites as "Anglos.") The educators in JDS also address issues of class and religion directly, but avoid discussing race and disability. This results in paradoxical patterns of inclusivity and exclusivity within the school. We first provide an overview of the school community, then turn to examine these patterns.

Juan Diego School (JDS) is an independent Catholic elementary school located in a major metropolitan area of the Western United States. Enrolling 100 students, $85 \%$ of whom identify as Latino and $62 \%$ whom qualify for free or reduced price lunch, JDS departs from other Catholic schools (regionally and nationally) in several key ways. First, it has a unique governance structure. In contrast with most Catholic schools, which operate in relationship with a parish community and within a system of Catholic schools (Gray and Gautier 2006), JDS operates under an independent board of directors and without a parish affiliation. Second, while most Catholic schools are financed through tuition and parish subsidies, JDS school draws only $14 \%$ of its funding from tuition, and $86 \%$ from various fundraising efforts. This allows JDS to serve significantly more students of low socioeconomic status than most Catholic schools. Third, JDS is independent in crafting its curricular approach and school structure, allowing it to be two-way immersion and to extend the school day and school year beyond what other Catholic schools are offering. Fourth, JDS explicitly recruits students to craft a student population that is primarily Latino and of low socioeconomic status. These distinctions affect admissions practices, as will be shown below. Fundamental Mission and Structure

13 Scanlan \& Palmer 
The leadership at JDS is explicitly oriented toward social justice education, reflecting what Marshall and Oliva (2006) describe as "moral outrage at the unmet needs of students and a desire for a caring community where relationships matter" (p. 7). Professional development activities, communications to parents, promotional materials, and fundraising endeavors consistently reflect a message of reducing marginalization. For instance, during one site visit I joined the faculty book club in their discussion of "Literacy with an Attitude" (Finn 1999). In a parent meeting that same day, Latino and Anglo parents both described the school as part of a larger effort to ameliorate social and educational inequities that Latino families in the neighborhood endured. Research participants, including teachers, administrators, board members, and parent volunteers, all expressed social justice orientations, the rhetoric of which place a value on inclusion.

These social justice orientations connect to the espoused mission of JDS, which is at once inclusive and exclusive. The formal mission statement frames the school as "community-based ... produc[ing] leaders ... providing a quality dual-language education ... for children of families with limited financial resources." In keeping with the two-way immersion model, this mission drives JDS to seek linguistic heterogeneity (approximately half Spanish-dominant and half English-dominant students). However, it also explicitly seeks financial homogeneity (two of every three students qualify for free or reduced price lunch). Moreover, while the formal mission does not state so explicitly, the school also directly seeks ethnic homogeneity: "We want $85 \%$ of our kids Latino ... internally we're explicit about that, and when we do admissions it's our focus," explains Richard, the school president since 2003. Thus, JDS seeks to recruit and retain a population that is diverse across language, but similar in being primarily Latinos of low socioeconomic status. The central goal of this $\mathrm{K}-5$ school is to provide students with the educational foundation that will lead them to college.

As a non-tuition-based private school that receives over $85 \%$ of its operating revenue from fundraising, JDS departs from the typical model of private (including Catholic) schools that rely on tuition-paying populations (Alt and Peter 2002). As opposed to elitist tendencies in these private schools, the niche that JDS seeks to serve is to be a high performing, academically rich bilingual school primarily serving Latino youth who are "economically disadvantaged." The financing model allows the school wide latitude in attracting students from families who lack the financial means to afford tuition, which is nominally set near the operational cost-per-pupil (between $\$ 6000$ and $\$ 7000$ ). Less than $5 \%$ of students pay this amount, and while all families are required to pay a nominal amount toward their tuition, JDS provides extensive scholarships to all families who

\section{Scanlan \& Palmer}


apply, so that no one is denied admission based on financial need. The school also provides reduced price lunch and after school programming at no cost to students.

Sister Rose, a founding board member, describes the origins of JDS. She recalls meetings beginning in 1995 of a "motley group of people" from a local Latino parish, a college, and public and private schools. The school was designed "for the Hispanic culture" who were not being served in either other Catholic schools or in area public schools. Strikingly, the principal of a local grade school was amongst this group of planners, linked in through her membership in the parish community. This planning group conceived of a school with a separate board of directors allowing it to be independent from the Archdiocese. Sister Rose explains the rationale: "We wanted our own pay scale and we wanted our own calendar ... We wanted a longer school day, a longer school year, and to pay our teachers a decent salary." After years of planning, involving community surveys, forums and discussion groups, as well as a feasibility study funded by a religious order, JDS opened with early elementary grades in 1999, and added a grade each year to build a K-5 school currently serving 100 students.

The key administrators in JDS are Richard, the school president since 2003, and Alita, the school principal since 2004. Richard, an Anglo, is primarily responsible for overseeing the fundraising of the school, and works with the board and with members of the broader community to promote the school and build support. Working for seven years as a school psychologist on top of a decade of teaching experience in two-way immersion schools, Alita, who is Latina, replaced the founding principal of JDS. She describes the JDS as nurturing a "spiritual, culturally relevant and caring environment" and nurturing strong academic achievement.

Several hallmarks distinguish the JDS community. Strong academic expectations and bi-literacy are emphasized throughout the school and at all grade levels. To support these expectations, students are taught in small classes and for longer amounts of time with an extended school day and year. In addition, families are systematically engaged at the classroom as well as the school level. The school hires a full time "Director of Graduate Support" to work with families as their children move from JDS into middle school, high school, and college. The student learning outcomes are positive. For instance, on the state standardized assessments in the subject areas of reading and math, all of the graduating class of fifth graders scored proficient or advanced, and no students in third or fourth grade scored lower than "partially proficient." Successfully Recruiting and Retaining Latino Families

Having provided this broader context for understanding the school community, we now turn to focus on the patterns of inclusivity and exclusivity reflected in the admissions practices in

\section{Scanlan \& Palmer}


JDS. Unlike MES, JDS is able to largely control its student population because it is a private religious school, therefore maintaining considerable discretion regarding admission of students (Mawdsley 2000). While linguistically heterogeneous, balanced between students who are native in English and those native in Spanish, the school is purposefully homogenous across dimensions of ethnicity and class. Discussing the admissions practices in JDS with Alita and Richard pointed to layered complexities beneath these two dimensions.

Regarding ethnicity, JDS seeks to primarily serve Latinos. Most of the teachers are Latino, and all are bilingual. As noted earlier, the vast majority of students identify as Latino (85\%), $14 \%$ identify as Anglo, and $1 \%$ as African American. This composition, at least to the degree of strongly attracting Latino families, is deliberate. All students apply to attend the school, and an admissions committee seeks to craft classes that are linguistically balanced and predominantly Latino. By contrast, Catholic school student bodies in the region are, on average, over $71 \%$ White, and only 17\% Latino (Charts 4 and 5 ).

This preference for recruiting and retaining Latino students, however, is not always transparently communicated within the JDS school community. While the promotional literature of the school make clear that it seeks to serve the common good of the "community by giving economically disadvantaged and linguistically diverse children a strong start," the school does not necessarily communicate this preference for Latino students clearly. Richard explains an anecdote showing the ambiguity in JDS around this issue:

One of our [former] parents ... she said to me "It just doesn't feel like this school is 50/50 [Latino/Anglo]. And I didn't say this to her, but in my mind and my heart, I was like, Yeah, and we were never intending to be. There is an opportunity for some Anglo families ... I don't know what our admissions brochure says right now, and I don't know how we address that. I'm not sure if we should.

Another parent, an Anglo who participated in this research, expressed a similar reaction, describing how she was looking for a Catholic school community that was diverse across some dimensions of race and ethnicity, and she was attracted to the bilingualism of JDS, but did not realize how predominantly Latino it was until she saw her child in a musical performance standing with his whole class, and suddenly realized that he was the only Anglo there.

In addition to recruiting a predominantly Latino student body, JDS invests considerable effort in retaining these families. Alita described how she supports parents in developing cross-cultural and cross-linguistic relationships, which she connects to the students' experiences in the school:

\section{Scanlan \& Palmer}


I think it's really important not to separate the parents by language. One of the things l've learned-l've been in dual immersion programs for a long time - is that the one factor that seems to change how the kids develop friendships ... it only seems to happen when parents develop cross-cultural friendships. If the parents develop cross-cultural friendships, the children seem to develop real cross-cultural friendships.

At the school level, Alita initiated efforts to foster these the cross-cultural relationships of parents focused on supporting their children's academic progress: "I want to teach them skills but I also want them to have a dialogue ... we have a lot of parents who are helping their child with homework in a language that they don't understand starting in kindergarten." Alita initiated small group meetings with parents. She conducted these on several days each month and organized them around the needs that parents articulated, such as supporting students' schoolwork. Parents were required to attend meetings, and Alita scheduled them to purposefully mix the groups across language and race. While the efforts were time-intensive, she expressed satisfaction that this investment was worthwhile, connected back directly to the goal of the school to prepare these students for college:

It is clear that families of Mexican origin support strongly education and support strongly that their child goes to the university. But there is a gap between what they know to do to make that happen. It's expressed as a priority, but their actions may not support it because they simply don't necessarily know the steps that it takes. So some of the things that we do here to try to support that.

For example, she described working with the parents to communicate homework expectations and teaching them how to engage with their child around academics:

I talk with parents a lot about how there needs to be a space for your child's education within what your family does. So you don't just pick up your child-and then go get groceries, and run errands, and stop off at the comadre's house, and get home at 8:30_...That your family needs to organize within the routine of what your family does. There's time that you say-OK we need to be home by 6:00 because, you know, César has to do homework, within the family that's what is going on at that time. .... Those are the kinds of things that families of Mexican origin don't necessarily know automatically how to do. As schools-what families do to do well in schools looks different in Mexico than it does in the United States. So teaching the families how to build that space is very important.

In sum, the efforts at the school level to engage and retain Latino families are very deliberate. The engagement seeks to foster bilingual interactions (and in particular cross-cultural 17 Scanlan \& Palmer 
relationships), in support of a unified student community and student learning.

These efforts at the school level to retain families are mirrored by teachers' actions at the classroom level. For instance, Andrew, an early elementary teacher, described innovative strategies of drawing family members from diverse socioeconomic backgrounds into the classroom to present stories of their own work experiences and life lessons to the students. Discussing her visit to the classroom, one parent research participant described this experience as providing a powerful opportunity for her to connect to her daughter's class. Significantly, Andrew's approach to this activity reflected an appreciation for the funds of knowledge within all families (ERIC Digest 1994; Moll and Gonzalez 2004; Rubinstein-Avila 2006).

In another instance, Anna, a teacher in the upper elementary grades, described how "frequent and informal" communication with all the families of her students allows her to respond quickly to problems and to build strong relationships with them:

I basically see all the parents twice a day, in the morning and after school ... Just like you how you learn lots of things from your neighbors from frequent and informal meetings ... That's something that's unique about this school. In other schools, you could see the parent of one of your students in the street and not even know that that's one of your students' parents. Here I see them twice a day.

In sum, JDS deliberately recruits a student body that is primarily Latino, and then proceeds to work at the school level and the classroom level to retain these students. Struggling to Address other Dimensions of Diversity

Excelling in efforts to serve Latino students, JDS has more mixed success in addressing other dimensions of diversity, such as racial and ethnic dimensions beyond Latino/Anglo considerations, as well as class and disability. Regarding race and ethnicity, JDS operated in a Latino/Anglo dualism. While $12 \%$ of students in other Catholic schools identified as Black, Asian, or Multiracial, only $1 \%$ of students in JDS identified as anything other than Latino or Anglo. Moreover, in explicit and implicit ways, JDS reinforced a Latino/Anglo dualism. When describing the school history, promotional materials explain that the school seeks to "honor Latino and Anglo cultures equally." In discussions of family engagement, research participants consistently emphasized building bridges between Anglo and Latino families. In repeated questioning about who was included and who was excluded in the school community, no research participant ever brought up dimensions of race and ethnicity that extended beyond classifications of Anglo or Latino.

With regard to students with special needs, JDS does not make any significant efforts at inclusion, either for diagnosed disabilities or undiagnosed barriers to learning. JDS has not 18 Scanlan \& Palmer 
developed a well-articulated service delivery plan for students with special needs, and many research participants at all levels (administrators, teachers, board members, and parents) described the school as unable to serve students with special needs. While this problem is endemic to Catholic schools, many such schools are directly attempting to address it (Crowley and Wall 2007; Durow 2007; Long et al. 2007; Scanlan in press; United States Conference of Catholic Bishops 2002), Service delivery to students with special needs is also emerging as a salient and understudied challenge in two-way immersion schools (Milian and Pearson 2005).

In contrast to the heightened attention to addressing Latino/Anglo dimensions of race and ethnicity, little attention was given to this dimension of diversity. No research participants could recall a student with a significant disability who had been a student in the school. Most research participants explained that the school simply was unequipped from a structural and a personnel standpoint to serve some students with disabilities, such as those with significant cognitive disabilities or with physical disabilities that precluded navigating stairs. Yet even for students with high incidence disabilities or undiagnosed barriers to learning who might make it past this initial screen and be admitted, JDS lacked an articulated approach to delivering educational services to them.

The lack of a clear service delivery plan for students with special needs is paradoxical because the school has several features that make it a strong learning environment for such students. For instance, the principal, as a former school psychologist, is experienced at analyzing student needs and designing appropriate accommodations. In addition, classroom observations and interviews indicate that many teachers exhibit strong arrays of strategies for differentiating instruction and providing accommodations for students who are struggling (i.e. behaviorally, academically, emotionally).

The data showed that this lack of a service delivery plan resulted in highly variable experiences for students as they moved through the school. In some rooms, students who were struggling would experience relatively inclusive settings that accommodated a wide range of learning styles and teachers who collaborated with outside resources such as the principal or the family to address their needs. In other rooms, they encountered classrooms with exclusionary practices; they were pulled out and sent to other teachers or to the office. Absent a clear service delivery model for students with special needs, the school fails to consistently serve students across this dimension of diversity.

The school community of JDS is highly focused on ensuring that the academic outcomes of the students are strong and that the school creates a college preparatory "incubator" for Latino 19 Scanlan \& Palmer 
youth, especially those in poverty. In the course of this pursuit, JDS engages in practices that are exclusionary, particularly toward students with exceptionalities and those that fall outside of the Latino/Anglo dichotomy. JDS is demonstrating important student outcomes, such as demonstrated academic success on standardized tests. A supportive and effective school environment inclusive of Latino youth in poverty could be considered an exemplar of social justice schooling. Paradoxically the cost of this, at JDS, is inclusion across these other dimensions of marginalization.

\section{Discussion}

These findings illustrate that nonlinguistic dimensions of diversity affect recruitment and retention in two-way immersion schools in multiple ways. Viewed through a critical epistemology, these findings complicate discourses of inclusivity and exclusivity in two-way immersion schools in particular, and social justice schooling in general. How does the field of social justice schooling interpret schools such as JDS that, by design, reduce some dimensions of marginalization while ignoring, or even exacerbating, other dimensions? Is it possible, with a social justice orientation, to take into account the students not being served by two-way immersion programs at schools like MES? In both cases, the marginalization that occurs is not accidental. JDS explicitly "does not serve" special needs children (and defines "special needs" as is convenient for them); MES' gatekeeping measures, both structural and attitudinal, maintain very different populations within and outside of two-way immersion classrooms. And yet both schools' two-way programs were founded in an explicit effort to address inequity and develop rich, diverse schooling environments for marginalized students-and both successfully do so, at least along some dimensions.

When compared to one another, both of these two-way immersion settings appears to successfully address at least some of the particular challenges faced at the other. MES, as a public school, has an articulated service delivery system for supporting children with special needs. No child is excluded from the school nor turned away for lack of services, although at times families have been known to move their special needs children out of the two-way program into the "mainstream" program in order to ease the burden on the child (two-way is seen as the more challenging program). The lottery for the two-way program is open to any child residing within the district, regardless of special need. Teachers in all MES classrooms expect to deal with a wide range of challenging students. There are special education classrooms at MES, although most children with identified special needs remain in regular education classes and are served by pull-out (English-speaking) resource specialists. While it is part of the discourse of the school that 20 Scanlan \& Palmer 
the "mainstream" classrooms receive more than their fair share of the "burden" of special needs children, there are children served by special education services in every classroom at the school. As a public school, MES does not have the option of turning away special needs children, while JDS, within a private school frame, has not yet recognized the exclusion of children with special needs as an issue of social justice or equity.

Meanwhile, while at MES there are Latino English- and Spanish-speaking children in the regular "mainstream" classrooms who were unable to gain entry into the elite two-way program supposedly designed to serve them, JDS does not turn away any Latino children, whether English or Spanish speaking. On the contrary, they specifically aim to recruit as many as they can into their school, while the rest of the Catholic schools in their region do very little to include or to serve Latino families. This mission of schools designed to serve Latino communities has historical precedent in both Catholic (Flores and Murillo 2001; San Miguel and Valencia 1998) and secular contexts (Friedman 1985). At MES, families with higher social capital gain entry more easily to the program; at JDS, it is the families with lower levels of social capital who are recruited and served most powerfully_and who in all likelihood otherwise would never have entered the private school world. This model of Catholic schools designed to cater to families of low socioeconomic status is a growing phenomena in the United States (Cattaro 2002; NativityMiguel Network 2007; Selected Programs for Improving Catholic Education (SPICE) 2000). Hence, considering JDS and MES each within their respective systems of schools, JDS is structured to serve those more marginalized, while MES in effect caters to those with more power.

Another contrast can be seen in the way the two schools address issues of race and ethnicity. In JDS, educators make efforts to directly address some of these issues by recruiting and serving children of Latino background. In this they act counter to the system of Catholic schools within which the school resides. Perhaps because it is an independent Catholic school only loosely affiliated with the Diocese, JDS cultivates space to address these issues more directly than other Catholic schools in the region. At the same time, it does so only within the Latino/ Anglo dualism. MES, meanwhile, is much more seriously constrained by the district in which it resides. Despite at least some staff members' convictions that race must be addressed in order to develop equitable learning spaces at MES, the district's policies prevent direct intervention. As a result, race is not directly addressed, and many staff members maintain problematic attitudes towards the African American children and families they serve.

A lens of critical epistemology illuminates contradictions and limitations of recruitment and retention practices in these two-way immersion settings across nonlinguistic dimensions of

\section{Scanlan \& Palmer}


diversity. JDS' success at drawing people into the private Catholic school system who would not otherwise be there is commendable; yet it is still a private school, with the ability to self-select and the right to exclude. MES' apparent success at drawing middle-class whites back into an urban school is also commendable; yet it continues to struggle to properly serve the students of color who have been there all along.

\section{Conclusion}

This analysis suggests that the espoused missions of the two-way immersion schools heighten awareness in these school communities around discrete dimensions of diversity while muting discourse around others. As Cummins (2000) argues, in the interests of improving the education of chronically underserved Spanish speaking Latino students, we can and should integrate bilingual programs as they did at MES. We need to transform them from subtractive, deficit-oriented transitional programs to additive, enrichment-oriented two-way immersion programs that become desirable options for the elite. We can and should build new, empowering programs from the ground up, basing them in the communities they are designed specifically to serve, as they did at JDS. There is a strong and growing body of research that reinforces the power of two-way immersion education for Latino students' academic success and bilingual/biliterate competency (Christian et al. 1997; Freeman 1998; Lindholm-Leary 2001; Pérez 2004).

However, it is not enough simply to build such programs. Without directly addressing issues of race and class and explicitly serving children along all lines of diversity present in a community, the program may end up serving the needs of those whose sense of entitlement most calls out to be served (Valdés 1997). The Latino students, the poor students, and any other group within the community (such as special needs students or African American students, as in JDS and MES) will once again be left most egregiously out of the equation, except insofar as they serve the needs of the dominant majority.

\section{Notes}

- M. Scanlan: Educational Policy and Leadership, College of Education, Marquette University, P.O. Box 1881, Milwaukee, WI 53201-1881, USA e-mail: martin.scanlan@marquette.edu

- Palmer: Bilingual/Bicultural Education, University of Texas, Austin, Austin, TX, USA 


\section{References}

Alt, M. N., \& Peter, K. (2002). Private schools: A brief portrait. Washington, DC: National Center for Education Statisticso.

Blank, R. (1990). Analyzing educational effects of magnet schools using local district data. Sociological Practice Review, 1, 40-51.

Blank, R., Levine, R., \& Steel, L. (1996). After 15 years: Magnet schools in urban education. In B. Fuller \& R. Elmore (Eds.), Who chooses, who loses? Culture, institutions and the unequal effects of school choice (pp. 154-172). New York: Teachers College Press.

Calderon, M. E., \& Minaya-Rowe, L. (2003). Designing and implementing two-way bilingual programs. Thousand Oaks, CA: Corwin Press.

California Department of Education. (2007). Data quest. Retrieved November 6, 2007, from http://dq.cde.ca.gov/dataquest/.

Capper, C. (1998). Critically oriented and postmodern perspectives: Sorting out the differences and applications for practice. Educational Administration Quarterly, 34(3), 354-378.

Cattaro, G. M. (2002). Catholic schools: Enduring presence in urban America. Education and Urban Society, 35(2), 100-110.

Center for Applied Linguistics. (2005). Center for Applied Linguistics Directory of Two-Way Immersion Programs. Retrieved June 27, 2005, from http://www.cal.org/twi/directory/.

Christian, D., Lindholm, K., Montone, C., \& Carranza, I. (1997). Profiles in two-way immersion education. McHenry, IL: Delta Systems Co, Inc.

Crowley, A. L. W., \& Wall, S. (2007). Supporting children with disabilities in the Catholic schools. Catholic Education: A Journal of Inquiry and Practice, 10(4), 508-522.

Cummins, J. (2000). Language, power and pedagogy: bilingual children in the crossfire. Clevedon, UK: Multilingual Matters.

Delgado Bernal, D. (2002). Critical race theory, Latino critical theory, and critical raced-gendered epistemologies: Recognizing students of color as holders and creators of knowledge. Qualitative Inquiry, 8(1), 105-126.

Durow, W. P. (2007). Including and serving students with special needs in Catholic schools: A report of practices. Catholic Education: A Journal of Inquiry and Practice, 10(4), 473-489.

ERIC Digest. (1994). Funds of knowledge: Learning from language minority households. ERICRIE0, 19940201.

Finn, M. (1999). Literacy with an attitude. Albany, NY: State University of New York Press.

Flores, S., \& Murillo, E. G. (2001). Power, language, and ideology: History and contemporary 
notes on the dismantling of bilingual education. The Urban Review, 33(3), 183-206.

Frattura, E., \& Capper, C. (2007). Leadership for social justice in practice: Integrated comprehensive services for all learners. Thousand Oaks, CA: Corwin Press.

Freeman, R. (1998). Bilingual education and social change. Clevedon, UK: Mulilingual Matters.

Friedman, N. (1985). The future of ethnic cultural pluralism in America: Two school-based models and scenarios-Jews and Chicanos. Urban Education, 20(2), 177-187.

Fuller, B., \& Elmore, R. (1996). Who chooses, who loses? Culture, institutions and the unequal effects of school choice. New York: Teachers College Press.

Garcia, E., \& Jensen, B. (2007). Language development and early education of young Hispanic children in the United States. Tempe, AZ: National Task Force on Early Childhood Education for Hispanicso.

Glesne, C. (1999). Becoming qualitative researchers. New York: Longman.

Gray, M., \& Gautier, M. (2006). Primary trends, challenges, and outlook: A report on U.S. Catholic elementary schools 2000-2005. Washington, DC: National Catholic Educational Associationo.

Guba, E., \& Lincoln, Y. (2001). Competing paradigms in qualitative research. In C. Conrad, J. G. Hawworth, \& L. Lattuca (Eds.), Qualitative research in higher education: Expanding perspectives (pp. 57-72). Boston: Pearson Custom Publishing.

Howard, E., Sugarman, J., \& Christian, D. (2003). Trends in two-way immersion education: $A$ review of the research (Report No. 63). Baltimore, MD: Center for Research on the Education of Students Placed At Risk (CRESPAR).

Kincheloe, J., \& McLaren, P. (2000). Rethinking critical theory and qualitative research. In N. Denzin \& Y. Lincoln (Eds.), Handbook of qualitative research (pp. 279-314). Thousand Oaks, CA: Sage Publications.

Ladson-Billings, G. (1999). Just what is critical race theory, and what's it doing in a nice field like education? In L. Parker, D. Deyhle, \& S. Villenas (Eds.), Race is-race isn't: Critical race theory and qualitative studies in education (pp. 7-30). Boulder, CO: Westview Press.

Ladson-Billings, G. (2005). Reading, writing, and race: Literacy practices of teachers in diverse classrooms. In T. McCarty (Ed.), Language, literacy, and power in schooling (pp. 133-150). Mahwah, NJ: Lawrence Erlbaum, Associates.

Lindholm-Leary, K. (2001). Dual language education. Clevedon, UK: Multilingual Matters.

Long, T., Brown, C., \& Nagy-Rado, A. (2007). Preparing special educators to assume collaborative and consultative roles. Catholic Education: A Journal of Inquiry and

24 Scanlan \& Palmer 
Practice, 10(4), 409-507.

Lynn, M., \& Adams, M. (2002). Introductory overview to the special issue critical race theory and education: Recent developments in the field. Equity and Excellence in Education, 35(2), 87-92.

Marshall, C., \& Oliva, M. (2006). Building the capacities of social justice leaders. In C. Marshall \& M. Oliva (Eds.), Leadership for social justice: Making revolutions in education (pp. 1-15). Boston: Pearson.

Mawdsley, R. D. (2000). Legal problems of religious and private schools (4th ed.). Dayton, $\mathrm{OH}$ : Education Law Association.

Maxwell, J. (1998). Designing a qualitative study. In L. Bickman \& D. Rog (Eds.), Handbook of applied social research methods (pp. 69-100). Thousand Oaks: Sage Publications.

Maxwell, J. (2001). Understanding and validity in qualitative research. In C. Conrad, J. G. Hawworth, \& L. Lattuca (Eds.), Qualitative research in higher education: Expanding perspectives. Boston: Pearson Publishing.

McLaren, P., \& Giarelli, J. (1995). Critical theory and educational research. Albany, NY: State University of New York Press.

Milian, M., \& Pearson, V. (2005). Students with visual impairments in a dual-language program: A case study. Journal of Visual Impairment and Blindness, 99(11), 715-719.

Moll, L., \& Gonzalez, N. (2004). Engaging life: A funds-of-knowledge approach to multicultural education. In J. A. Banks \& C. A. M. Banks (Eds.), Handbook of research on multicultural education (pp. 699-715). San Francisco: Wiley.

NativityMiguel Network. (2007). Executive summary report. Washington, DC: NativityMiguel Network of Schoolso.

Noguera, P. (2003). City schools and the American dream: Reclaiming the promise of public education. New York: Teachers College Press.

Oakes, J. (2005). Keeping track: How schools structure inequality (2nd ed.). New Haven: Yale University Press.

Olsen, L. (1987). Made in America. New York: New Press.

Orfield, G. (1981). Why it worked in Dixie: Southern school desegregation and its implications for the north. In A. Yarmolinsky, L. Lance, \& C. Schelling (Eds.), Race and schooling in the city. Cambridge, MA: Harvard University Press.

Orfield, G., \& Lee, C. (2005). Why segregation matters: Poverty and educational inequality. Cambridge, MA: Harvard University, The Civil Rights Projecto.

25 Scanlan \& Palmer 
Ovando, C. (2003). Bilingual education in the United States: Historical development and current issues. Bilingual Research Journal, 27(1), 1-25.

Palmer, D. (2004). Educating for equity in a dual immersion classroom: "No interrumpas!" Unpublished Dissertation, University of California, Berkeley, CA.

Palmer, D. (2005). Race, power, and equity in a diverse urban elementary school with a dual immersion "strand" program. Paper presented at the American Education Research Association Annual Meeting.

Palmer, D. (2008). Building and destroying students' 'academic identities': The power of discourse in a two-way immersion classroom. Qualitative Studies in Education, 21(6), 647-667.

Perez, B. (2004). Becoming biliterate: A study of two-way bilingual immersion education. Mahwah, NJ: Lawrence Erlbaum Associates.

Petrovic, J. (2005). The conservative restoration and neoliberal defenses of bilingual education. Language Policy, 4(4), 395-416.

Ramirez, J. D., Yuen, S., \& Ramey, D. R. (1991). Final report: Longitudinal study of structured immersion strategy, early-exit, and late-exit transitional bilingual education programs for language-minority children. National Association of Bilingual Education Journal, 8, 15-34.

Rolon, C. A. (2003). Educating Latino students. Educational Leadership, 60(4), 40-43.

Rolon-Dow, R. (2005). Critical care: A color(full) analysis of care narratives in the schooling experiences of Puerto Rican girls. American Educational Research Journal, 42(1), 77-111.

Rossell, C. H. (1990). The carrot or the stick for school desegregation policy: Magnet schools vs. forced busing. Philadelphia: Temple University Press.

Rubinstein-Avila, E. (2006). Connecting with Latino learners. Educational Leadership, 63(5), 38-43.

Rubio, O. (1995). "Yo soy voluntaria": Volunteering in a dual-language school. Urban Education, 29, 396-409.

San Miguel, G., \& Valencia, R. (1998). From the treaty of Guadalupe Hidalgo to Hopwood: The educational plight and struggle of Mexican Americans in the Southwest. Harvard Educational Review, 68(3), 353-412.

Sapon-Shevin, M. (2003). Inclusion: A matter of social justice. Educational Leadership, 61(2), 25-28.

Sapon-Shevin, M. (2007). Widening the circle: The power of inclusive classrooms. Boston: 


\section{Beacon Press.}

Scanlan, M. (2008). Is the perfect the enemy of the good? Exclusivity in socially just schools. Paper presented at the Annual Meeting of the American Educational Research Association.

Scanlan, M. (in press). Emerging trends of inclusive Catholic schools. In P. Bauch \& T. Hunt (Eds.), Catholic schools in the public interest: Past, present, future. Charlotte, NC: Information Age Publishers.

Scanlan, M., \& Palmer, D. (2007). Race, power, and (In)equity within two-way immersion settings. Paper presented at the University Council of Educational Administration.

Schofield, J. (1995). Review of research on school desegregation's impact on elementary and secondary school students. In J. Banks \& C. Banks (Eds.), Handbook of research on multicultural education. New York: MacMillan.

Selected Programs for Improving Catholic Education (SPICE). (2000). Integrating the social teaching of the Church into Catholic schools. Retrieved July 27, 2005, from http://www.ncea.org/newinfo/awards/spice/spice_00/default.asp.

Senesac, B. V. K. (2002). Two-way bilingual immersion: A portrait of quality schooling. Bilingual Research Journal, 26(1), 1-17.

Solorzano, D. G., \& Yosso, T. (2002). Critical race methodology: Counter-storytelling as an analytical framework for educational research. Qualitative Inquiry, 8(1), 23-44.

Theoharis, G. (2007). Social justice educational leaders and resistance: Toward a theory of social justice leadership. Educational Administration Quarterly, 43(2), 221-258.

United States Conference of Catholic Bishops. (2002). Welcome and justice for persons with disabilities: A framework of access and inclusion. Retrieved July 9, 2005, from http://www.nccbuscc.org/doctrine/disabilities.htm.

Valdes, F. (1996). Latina/o Ethnicities, critical race theory, and post-identity politics in postmodern legal culture: From practices to possibilities. La Raza Law Journal, 9(1), 1-31.

Valdés, G. (1997). Dual language immersion programs: A cautionary note concerning the education of language-minority students. Harvard Educational Review, 67(3), 391-429.

Villenas, S., Deyhle, D., \& Parker, L. (1999). Critical race theory and praxis: Chicano(a)/Latino(a) and Navajo struggles for dignity, educational equity, and social justice. In L. Parker, D. Deyhle, \& S. Villenas (Eds.), Race is-race isn't : Critical race theory and qualitative studies in education (pp. 31-52). Boulder, CO: Westview Press.

Wolcott, H. F. (1990). Writing up qualitative research. Newbury Park, CA: Sage. 
Zentella, A. C. (1997). Latino youth at home, in their communities, and in school: The language link. Education and Urban Society, 30, 122-130. 
Appendix

Table 1

Race ethnicity in MES

\begin{tabular}{|l|c|c|c|}
\hline & School-wide & TWI classes & "Mainstream" classes \\
\hline Latino & 133 & 60 & 73 \\
\hline & $38 \%$ & $50 \%$ & $32 \%$ \\
\hline African American & 105 & 6 & 99 \\
\hline & $30 \%$ & $5 \%$ & $43 \%$ \\
\hline White American & 98 & 54 & 44 \\
\hline & $28 \%$ & $45 \%$ & $19 \%$ \\
\hline Other (API, Asian, etc.) & 14 & 0 & 14 \\
\hline & $4 \%$ & - & $6 \%$ \\
\hline
\end{tabular}

\section{Chart 1}

Racial/ethnic diversity schoolwide in MES

Race ethnicity schoolwide in

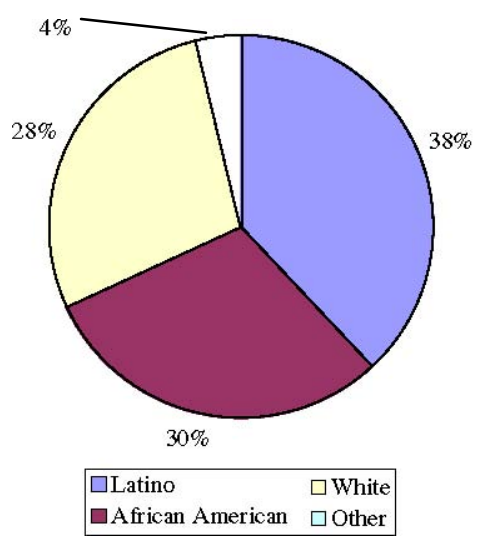

29 Scanlan \& Palmer 


\section{Chart 2}

Racial/ethnic diversity in two-way immersion sector of MES

Race ethnicity in the two-way immersion sector of MES

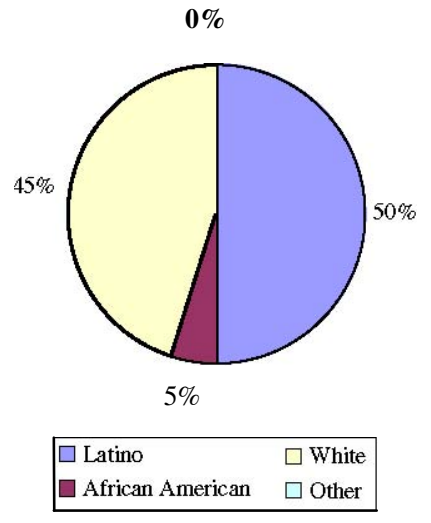

\section{Chart 3}

Racial/ethnic diversity in mainstream sector of MES

Race ethnicity in mainstream sector of MES

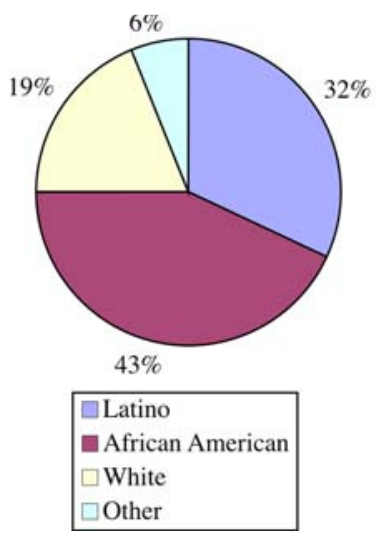

30 Scanlan \& Palmer 
Chart 4

Racial/ethnic diversity in JDS

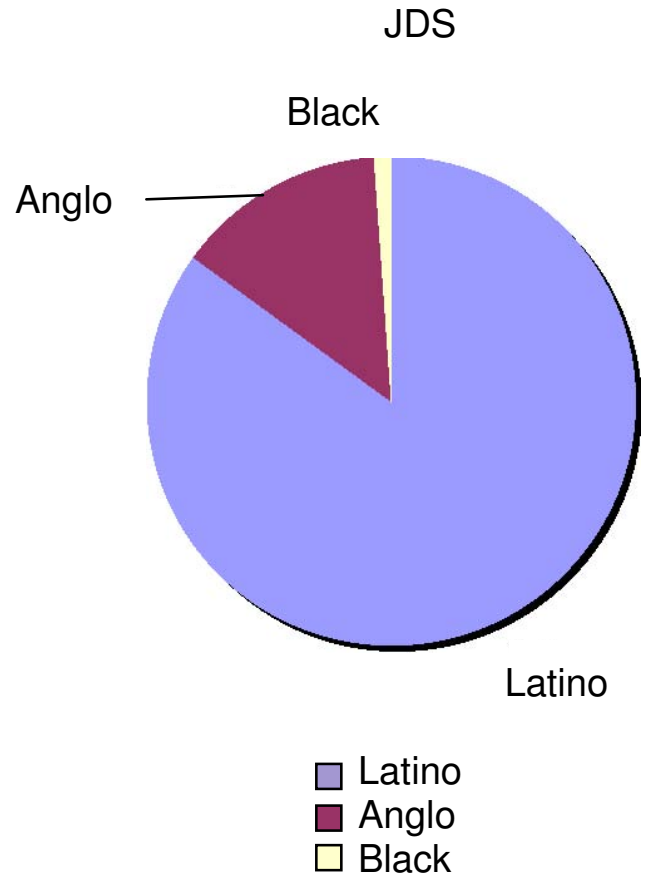

31 Scanlan \& Palmer 


\section{Chart 5}

Racial/ethnic diversity in area catholic schools

\section{Area Catholic Schools}

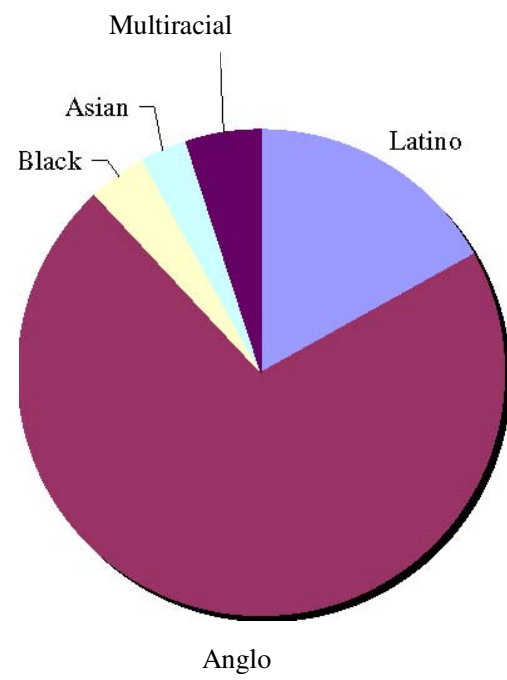

$\begin{array}{ll}\square \text { Latino } & \square \text { Asian } \\ \square \text { Anglo } & \\ \square \text { Multiracial }\end{array}$

